\title{
Influence Factors of Aluminum-Slag Interfacial Reaction Under Electric Field
}

\author{
Xin-Yu Lv ${ }^{1} \cdot$ An-Ping Dong ${ }^{1} \cdot J_{u n}$ Wang $^{1} \cdot$ Da Shu $^{1} \cdot$ Bao-De Sun $^{1}$
}

Received: 2 November 2016/Revised: 10 March 2017/Published online: 11 May 2017

(C) The Chinese Society for Metals and Springer-Verlag Berlin Heidelberg 2017

\begin{abstract}
The interfacial reaction between aluminum melt and molten slag under an electric field plays a significant role in aluminum electro-slag refining. Here we studied this interfacial reaction within 680 and $820{ }^{\circ} \mathrm{C}$ under an electric field between 0 and $9 \mathrm{~V}$. The evolution of aluminum composition was analyzed by inductively coupled plasma atomic emission spectroscopy. The dominant factor during the interfacial reaction was identified through orthogonal experiments, in which the slag-to-aluminum mass ratio, initial silicon concentration, electric voltage, reaction time, and temperature were selected as the influence factors. The greatest influence factor on the interfacial reaction was found to be the reaction time. Also, single-factor experiments revealed that the reaction kinetic processes largely obeyed an irreversible kinetic model, and the silicon removal efficiency was enhanced by increasing the voltage and slag/metal ratio.
\end{abstract}

KEY WORDS: Molten salts; Interfacial reaction; Silicon; Electric field; Aluminum; Kinetic model

\section{Introduction}

As aluminum has become one of the most widely used nonferrous metals [1-6], there is an increasing demand for ingots of highly controlled impurity elements [7-9]. Electro-slag refining (ESR) is an efficient process for alloy purification and has been extensively applied into steel and titanium refining. The key to understand and improve the ESR process is the slag-metal interfacial reaction [10], which has been studied extensively.

An early study on electrode polarization during direct current (DC) electro-slag melting suggested that the anodic

Available online at http://link.springer.com/journal/40195.

An-Ping Dong

apdong@sjtu.edu.cn

$\triangle$ Jun Wang

junwang@sjtu.edu.cn

1 Shanghai Key Laboratory of Advanced High-Temperature Materials and Precision Forming, Shanghai Jiao Tong University, Shanghai 200240, China reaction was a Faradic process that resulted in concentration polarization [11]. To study the process of droplet formation, Troyanskyy physically modeled the interfacial mass transfer with unsteady-state diffusion equations by using an icy electrode and vegetable oil (as slag) and identified the dominant stage in the refining process to be film formation, in addition to other tested processes of film tearing, film accumulation, and droplet takeoff [12]. Mitchell examined the oxide inclusions in ingots during the electro-slag process and found they resulted from a combination of chemical and electrochemical reactions [13]. Interfacial tension contributed to eliminating non-metallic inclusions from aluminum during ESR [14]. Although interfacial reaction plays a dominant role in electro-slag remelting/refining, there are no more investigations into the type of interfacial reaction, due to the difficulty in practical experimental process. However, here is rare investigation on aluminum ESR and no report about the interfacial reaction of aluminum ESR.

In addition to ESR, interfacial reactions between slag and molten metals are vital in other metallurgical processes [15-18]. Park et al. [19] investigated the kinetics of the 
reaction between $\mathrm{Fe}-\mathrm{Al}$ and $\mathrm{SiO}_{2}-\mathrm{Al}_{2} \mathrm{O}_{3}-\mathrm{CaO}$ slag, and White studied the mass transfer and transient interfacial phenomena in silicon refining under mechanical stirring [20].

Although the above-mentioned works shed some light on the interfacial reaction mechanism, there is no study about the influence of electric field on the interfacial reaction during aluminum ESR. Our recent experiments indicate that aluminum ESR using new LiCl-containing slag has significant effects on silicon removal. Nevertheless, the interfacial mechanism needs further exploration. Due to the complexity in ESR, we simplified the interfacial reaction as a reaction between aluminum melt and slag. The electric field most possibly plays an important role in interfacial reactions. Therefore, investigation on interfacial reaction under an electric field helps to understand the interfacial reaction mechanism of ESR. The primary objective of this study was to understand the impact factors on the interfacial reaction under a DC electric field [21]. The concentration of silicon impurity was selected as an indicator to estimate the extent of interfacial reaction. Based on single-factor experiments, we also discussed the kinetics of the interfacial reactions, as well as the effects of mass ratio and voltage on interfacial reactions.

\section{Experimental and Methods}

The slag composed of analytical-grade $\mathrm{LiCl}, \mathrm{NaCl}$, and $\mathrm{KCl}$ powders was dehydrated at about $423 \mathrm{~K}\left(150{ }^{\circ} \mathrm{C}\right)$ for $48 \mathrm{~h}$. Aluminum samples with $0.38 \mathrm{wt} \% \mathrm{Si}$ were prepared from commercial 8021A aluminum rods (Southwest Aluminum Holdings Ltd), and samples with 0.22 and $0.44 \mathrm{wt} \% \mathrm{Si}$ were obtained from castings prepared in a pittype resistance furnace.

Figure 1a shows the schematic diagram of the reaction unit used here, which consists of an alumina crucible, a lid with two 3-mm-diameter holes, two 1-mm-diameter molybdenum electrodes sheathed with alumina, and a $25-\mathrm{V}$ DC power source. During the experiments, the voltage was tuned manually through the power source. The key unit shown in Fig. 1a was placed into the pit-type resistance furnace, in which the temperature was controlled by a proportional-integral-derivative (PID) controller connected to a type- $K$ thermocouple adjacent to the crucible. The orthogonal experimental parameters are summarized in Table 1. The amount of molten salts used to remove silicon varied from 0.2 to 0.6 , which corresponded to the range of the mass ratio, $R$ (mass of salt powders to aluminum charged in the crucible). The onset of current flow was set as zero on timescale.

Before each interfacial reaction, an aluminum sample and slag were separately put into two alumina crucibles, heated to the preset temperature in a pit-type furnace and held there for $30 \mathrm{~min}$. Then, the slag was poured into the crucible containing the aluminum melt. When two molybdenum electrodes were inserted into the slag and aluminum melt, the power was turned on and timing was started. Once the reaction time reached the preset level, the crucible was removed from the furnace and cooled in air.

The dominant factor was identified through orthogonal experiments, in which temperature, reaction time, voltage, $R$, and the concentrations of $\mathrm{LiCl}$ and $\mathrm{Na}_{2} \mathrm{~B}_{4} \mathrm{O}_{7}$ were considered as the influence factors. A $6^{5}$ orthogonal table involving six factors and five levels was designed and is summarized in Table 1. To study the interfacial kinetic process and further clarify the influence of each factor, we also conducted single-factor experiments, in which the slag was fixed at $32 \% \mathrm{LiCl}-\mathrm{NaCl}-\mathrm{KCl}$ (Table 2). In Table 2, MS, $V$, and $t$ represent the mass of the aluminum sample, the voltage, and reaction time, respectively.

The concentration of Si impurity was determined by inductively coupled plasma (ICP) and was used to evaluate the reaction progress and silicon removal efficiency. The positions of samples for ICP are shown in Fig. 1b. The samples were observed on a scanning electron microscope (SEM).

\section{Results and Discussion}

\subsection{Dominant Factors at the Interfacial Reactions}

Figure 2a displays the range of silicon concentration as a response to the variation of each factor in the orthogonal experiments. Specifically, mass ratio $(R), V, T, t, \mathrm{NB}$, and $\mathrm{LiCl}$ represent the slag-to-metal mass ratio, voltage, temperature, time (in minute), mass percentage of $\mathrm{Na}_{2} \mathrm{~B}_{4} \mathrm{O}_{7}$ in the slag, and mass percentage of $\mathrm{LiCl}$ in the slag, respectively. Based on the diminishing order of significance, these factors rank as follows: $t>\mathrm{NB}>\mathrm{LiCl}=V$ $>T>R$. Specifically, $t$ has the most significant influence on the interfacial reaction, whereas $\mathrm{LiCl}, V, T$, and $R$ have roughly identical impacts. The strong dependence of interfacial reactions on reaction time suggests that the reduction rate of silicon concentration at the interface surpasses the increment rate of silicon concentration due to diffusion from the bulk aluminum melt. This phenomenon indicates that silicon diffusion is pivotal in the interfacial reactions. The detailed silicon dependence of $t, V, \mathrm{LiCl}$, and NB is shown in Fig. 2b-e.

As shown in Fig. $2 b$, the silicon concentration increases within the reaction time of $30 \mathrm{~min}$, but decreases within the reaction time of 30-70 min. Moreover, the silicon concentration slightly increases with the voltage elevated from 1 to $3 \mathrm{~V}$, but decreases sharply with voltage increasing 

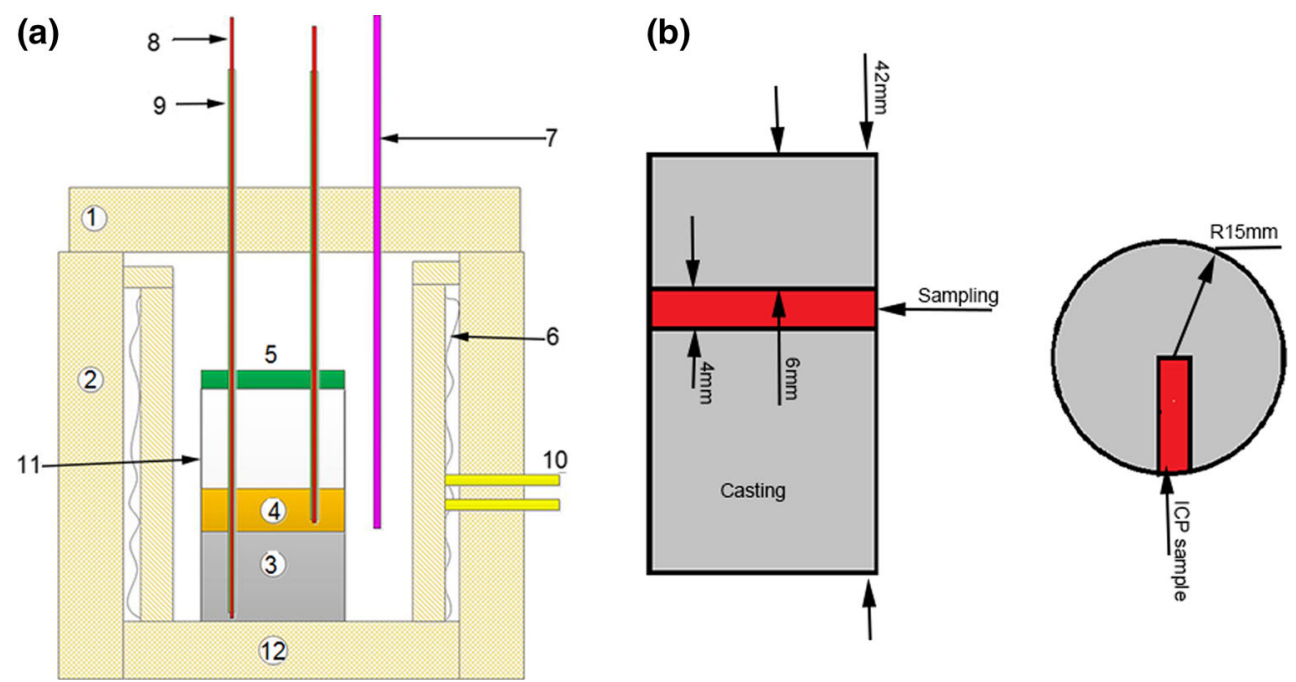

Fig. 1 Schematic diagram of the experimental equipment (a 1,2,6,10, and 12: components of the resistance furnace, 3 aluminum melt, 4 slag, 5 lid of crucible, $7 \mathrm{~K}$-type thermocouple, 8 molybdenum wire, 9 alumina sheath), positions of the samples for ICP b

Table 1 Orthogonal experimental parameters

\begin{tabular}{ll}
\hline Factors & Levels \\
\hline Reaction time (min), $t$ & $3,15,30,50,70$ \\
Temperature $\left({ }^{\circ} \mathrm{C}\right)$ & $680,700,730,760,790$ \\
$\mathrm{LiCl}(\mathrm{wt} \%)$ & $23,26,29,32,35$ \\
$\mathrm{Na}_{2} \mathrm{~B}_{4} \mathrm{O}_{7}(\mathrm{wt} \%)$ & $0,1,5,10,18$ \\
Mass ratio (slag mass/aluminum), $R$ & $0.2,0.3,0.4,0.5,0.6$ \\
\hline
\end{tabular}

from 3 to $5 \mathrm{~V}$ (Fig. 2c). The silicon concentration is minimized when $\mathrm{LiCl}$ is $32 \mathrm{wt} \%$ (Fig. 2d). The evaporation is less severe at $32 \mathrm{wt} \% \mathrm{LiCl}$ than at $35 \mathrm{wt} \% \mathrm{LiCl}$ and has the similar properties with eutectic composition. Therefore, the slag with $32 \mathrm{wt} \% \mathrm{LiCl}$ was used in the following singlefactor experiments. Figure $2 \mathrm{e}$ shows that the NB inhibits the elimination of silicon from aluminum. Addition of $\mathrm{Na}_{2} \mathrm{~B}_{4} \mathrm{O}_{7}$ improves the slag viscosity and in turn inhibits the interfacial diffusion. Our previous investigations indicate that NB reduces the purification efficiency and quality of castings in the ESR of LiCl-containing slag.

In industrial ESR experiments, the extent of silicon content reduction decreased about $17 \%$ using slag containing $30 \mathrm{wt} \% \mathrm{NB}$, and the quality of castings was reduced significantly as shown in Fig. 3.

\subsection{Interfacial Kinetic Process}

As shown in Fig. 4, the silicon concentration reduction rate follows a function of exponential decay and is strongly dependent on reaction temperature. Specifically, at 700 and $760{ }^{\circ} \mathrm{C}$, the silicon concentrations both drop rapidly from 0.22 to $0.14 \mathrm{wt} \%$ in the first $10 \mathrm{~min}$ and then remain constant. The micrographs of the samples changed significantly after the purification (Fig. 5). The size and quantity of intermetallic phases at grain boundaries both decrease obviously. At $820^{\circ} \mathrm{C}$, similar silicon concentration reduction was completed in only $5 \mathrm{~min}$. According to the reaction kinetics theory, we assume there is a type of one-order reaction in Fig. 4. To verify this assumption, we fitted the experimental results using different reaction orders $(n>1$, $n<1, n=1$ ) as follows:

$$
\begin{aligned}
& (1 /(1-n))\left[(\text { wt pet Si })^{(1-n)}-(\text { wt pet } \mathrm{Si})_{0}^{(1-n)}\right] \\
& \quad=-k(A / V) t(n \neq 1),
\end{aligned}
$$

where (wt pct $\mathrm{Si})_{0}$ and (wt pct $\mathrm{Si}$ ) are the silicon concentrations before and after the reaction with aluminum, respectively. Results show $n=1$ yields the best fit, which agrees well with previous findings that most metallurgical reactions are of first order.

Table 2 Single-factor experiments parameters

\begin{tabular}{ll}
\hline Invariable variant & Variable variant \\
\hline MS $(25 \mathrm{~g}), V(5 \mathrm{~V}), R(1), \mathrm{Si}(0.22 \mathrm{wt} \%)$ & $t(1,2,3,5,7,10,20 \mathrm{~min}), T\left(700,760,820{ }^{\circ} \mathrm{C}\right)$ \\
MS $(25 \mathrm{~g}), V(5 \mathrm{~V}), \mathrm{Si}(0.4 \mathrm{wt} \%), t(3 \mathrm{~min})$ & $R(0.2,0.4,0.6)$ \\
MS $(25 \mathrm{~g}), V(5 \mathrm{~V}), R(1), \mathrm{Si}(0.4 \mathrm{wt} \%)$ & $t(1,2,3,5,7,10,20 \mathrm{~min}), T\left(700,760,820{ }^{\circ} \mathrm{C}\right)$ \\
MS $(80 \mathrm{~g}), T\left(700{ }^{\circ} \mathrm{C}\right), R(1), \mathrm{Si}(0.4 \mathrm{wt} \%), t(3 \mathrm{~min})$ & $V(0,1,3,5,7,9 \mathrm{~V})$ \\
\hline
\end{tabular}



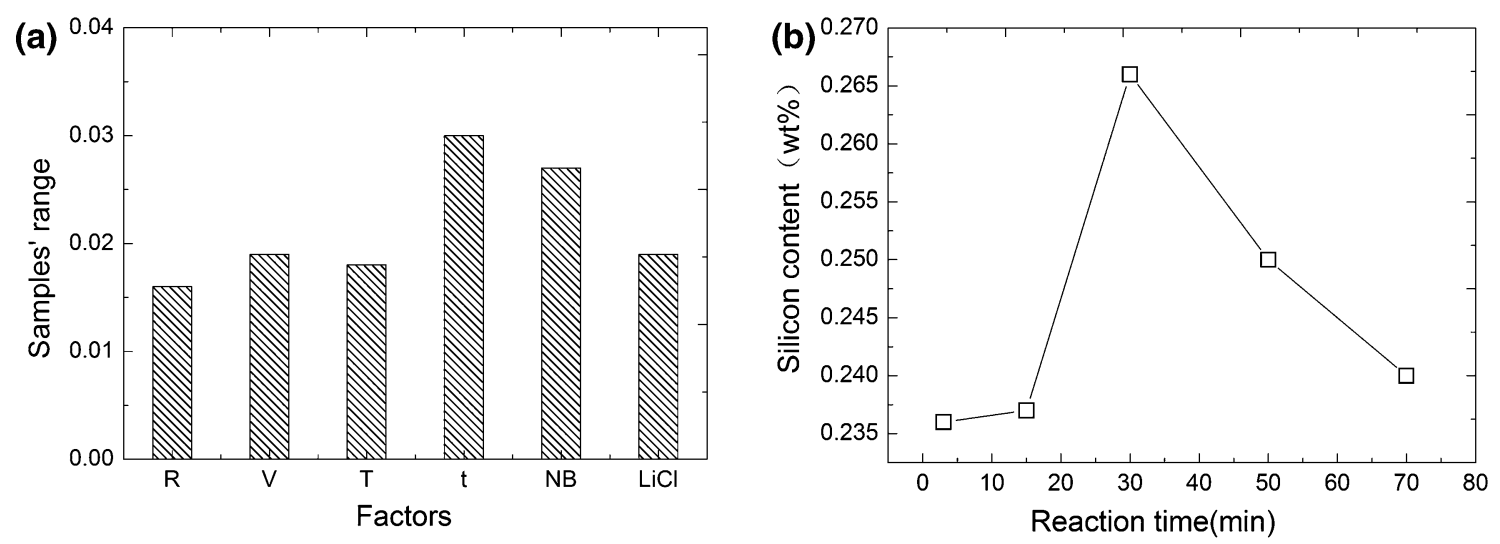

(c)

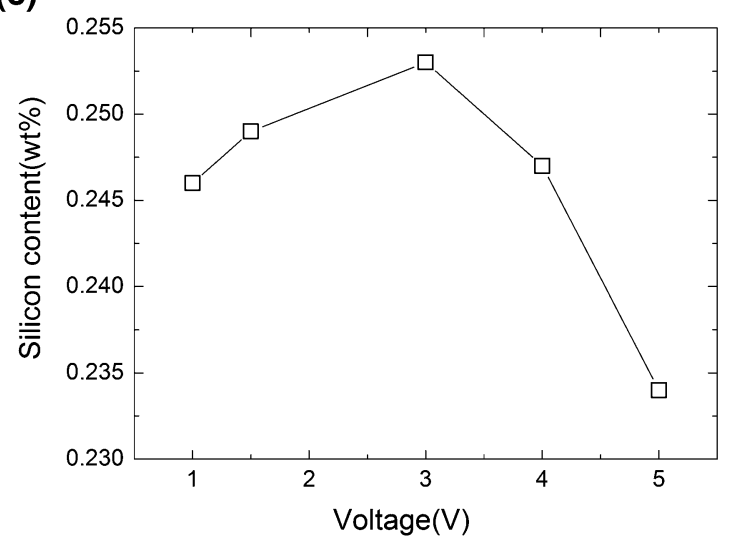

(d)
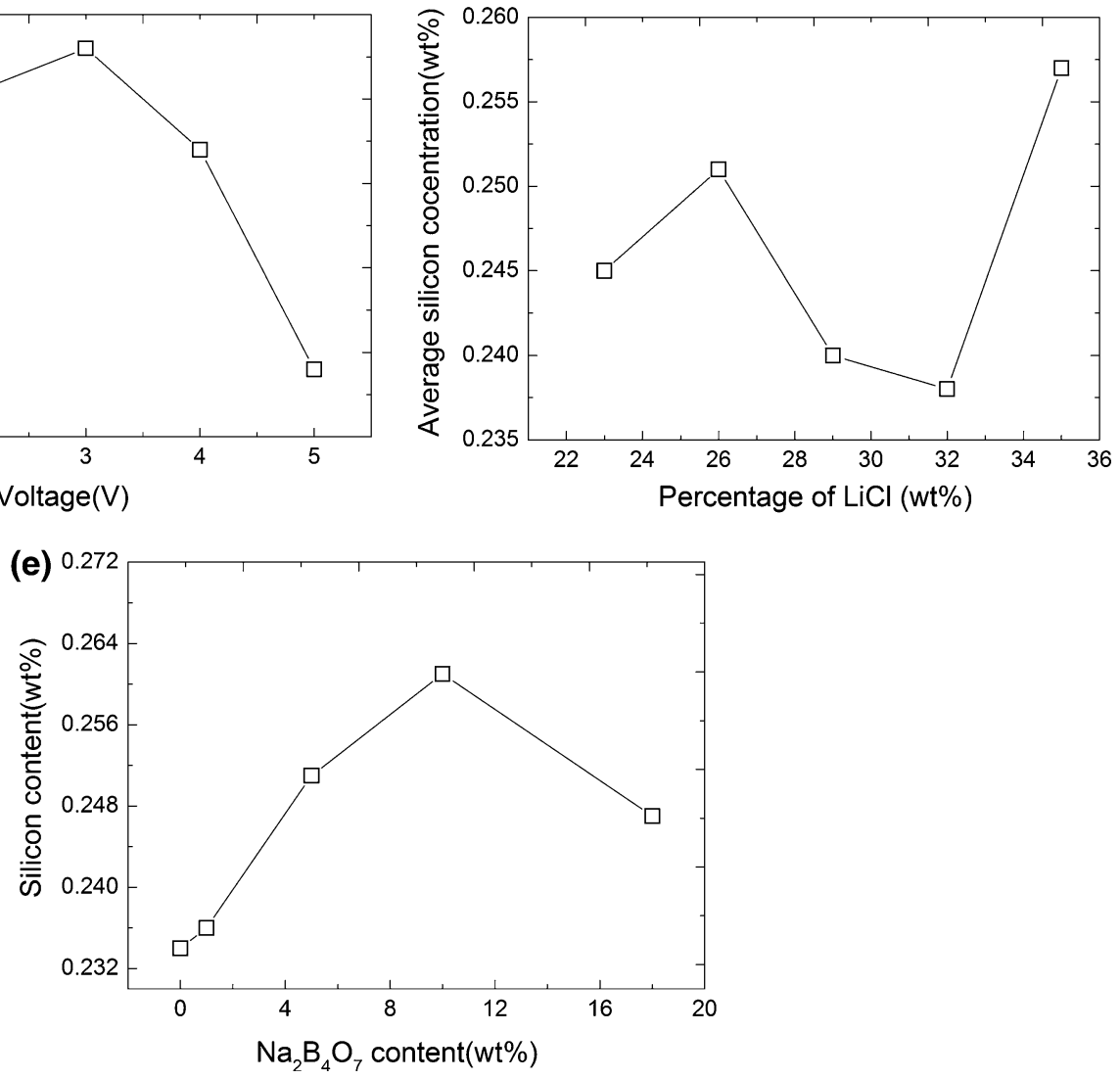

Fig. 2 Samples range in the orthogonal experiments a, effects of reaction time $\mathbf{b}$, electrical voltage $\mathbf{c}$, percentage of $\mathrm{LiCl}_{\mathbf{d}} \mathbf{\mathbf { N }} \mathrm{Na}_{2} \mathrm{~B}_{4} \mathrm{O}_{7}$ content e on silicon concentration

The irreversible kinetic equations can be expressed as follows [22]:

$(V / A) \ln \left(\left(C_{0}-C_{\mathrm{e}}\right) /\left(C_{t}-C_{\mathrm{e}}\right)\right)=k_{\mathrm{ov}} t$

$Y \ln Z=k_{\mathrm{ov}} t\left[Y=V / A, Z=\left(C_{0}-C_{\mathrm{e}}\right) /\left(C_{t}-C_{\mathrm{e}}\right)\right]$,

where $V$ is the volume of the aluminum sample, $A$ is the interfacial area, $C_{0}$ is the initial silicon concentration, $C_{\mathrm{e}}$ is the silicon concentration at the equilibrium state, $C_{t}$ is the silicon concentration at time $t$, and $k_{\mathrm{ov}}$ is the overall mass transfer coefficient.
The left side of Eq. (3) was plotted as a function of time for $25 \mathrm{~g}$ of Al-0.22Si\% samples at 700,760 , and $820{ }^{\circ} \mathrm{C}$ in Fig. 6. Each set of experimental data roughly conforms to a linear regression. From the slope of each line, the silicon mass transfer coefficient at different temperatures can be calculated. The overall mass transfer of silicon at 700, 760, and $820^{\circ} \mathrm{C}$ is $1.11 \times 10^{-4}, \quad 1.055 \times 10^{-4}$, and $0.88 \times 10^{-4} \mathrm{~m} / \mathrm{s}$, respectively, suggesting that the mass transfer coefficient decreases slightly with the temperature rise. 
(a)

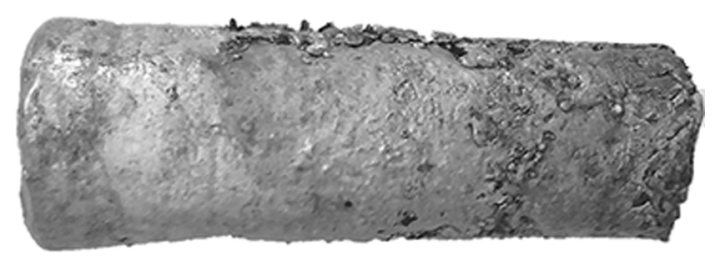

(b)

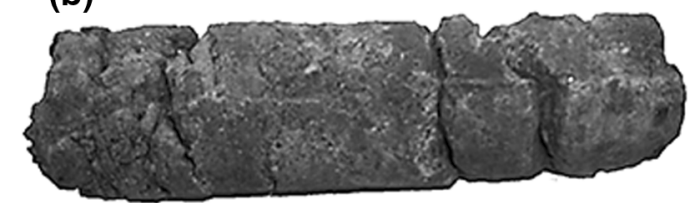

Fig. 3 Castings produced by different compositions slag, without $\mathrm{Na}_{2} \mathrm{~B}_{4} \mathrm{O}_{7}$ a, with 30 wt $\% \mathrm{Na}_{2} \mathrm{~B}_{4} \mathrm{O}_{7} \mathbf{b}$

As shown in Fig. 6d, the activation energy calculated from the slope of $\ln k$ versus $1000 / T$ [23, 24] is $E_{\mathrm{a}}=15.71 \mathrm{~kJ} / \mathrm{mol}$, which is lower compared with other studies $[25,26]$. Khaliq suggests that the reaction with activation energy $<100 \mathrm{~kJ} / \mathrm{mol}$ is a mass-transfer-controlled reaction. Since the electrochemical reaction rate is large at high temperature and the activation energy is relatively lower, the mass transfer of silicon is the ratecontrolling step in the aluminum-salt interfacial reactions $[24,27]$. Interfacial reaction process is illustrated in Fig. 7. Silicon concentration at the interface decreases after the silicon- $\mathrm{Cl}_{2}$ interfacial reaction. The silicon concentration distribution after the rapid interfacial reaction is similar to the left part in Fig. 7. If silicon atom transfers continuously to the interface, the interfacial reaction continues. The above results provide useful information for the improvement of interfacial reaction to some extent.

As shown in Fig. 8, the silicon concentration monotonically drops in the first $10 \mathrm{~min}$ (similar as in Fig. 3), but the change after 10-min reaction is similar to that in Fig. 2b, except there is higher initial silicon concentration in the case of Fig. 8. Our results suggest that the temporal change of silicon concentration is strongly dependent on the initial silicon concentration, and the reaction kinetics during the first 10 min obeys an irreversible kinetic model.
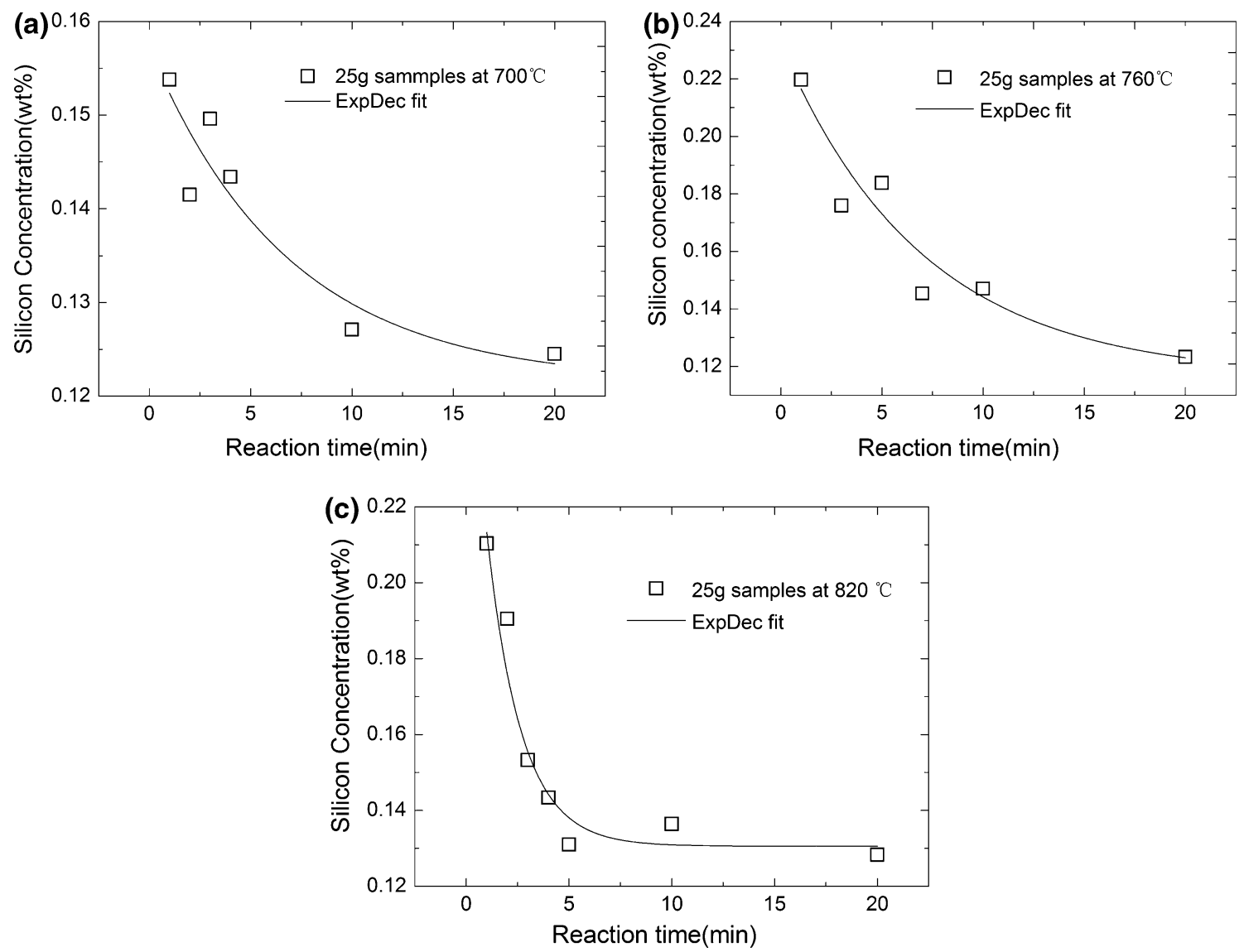

Fig. 4 Variation of the silicon concentration over the reaction time in the single-factor experiments: a mass of $25 \mathrm{~g}$ samples at $700{ }^{\circ} \mathrm{C}, \mathbf{b}$ mass of $25 \mathrm{~g}$ samples at $760{ }^{\circ} \mathrm{C}$, c variation in the silicon content at $820^{\circ} \mathrm{C}$ 

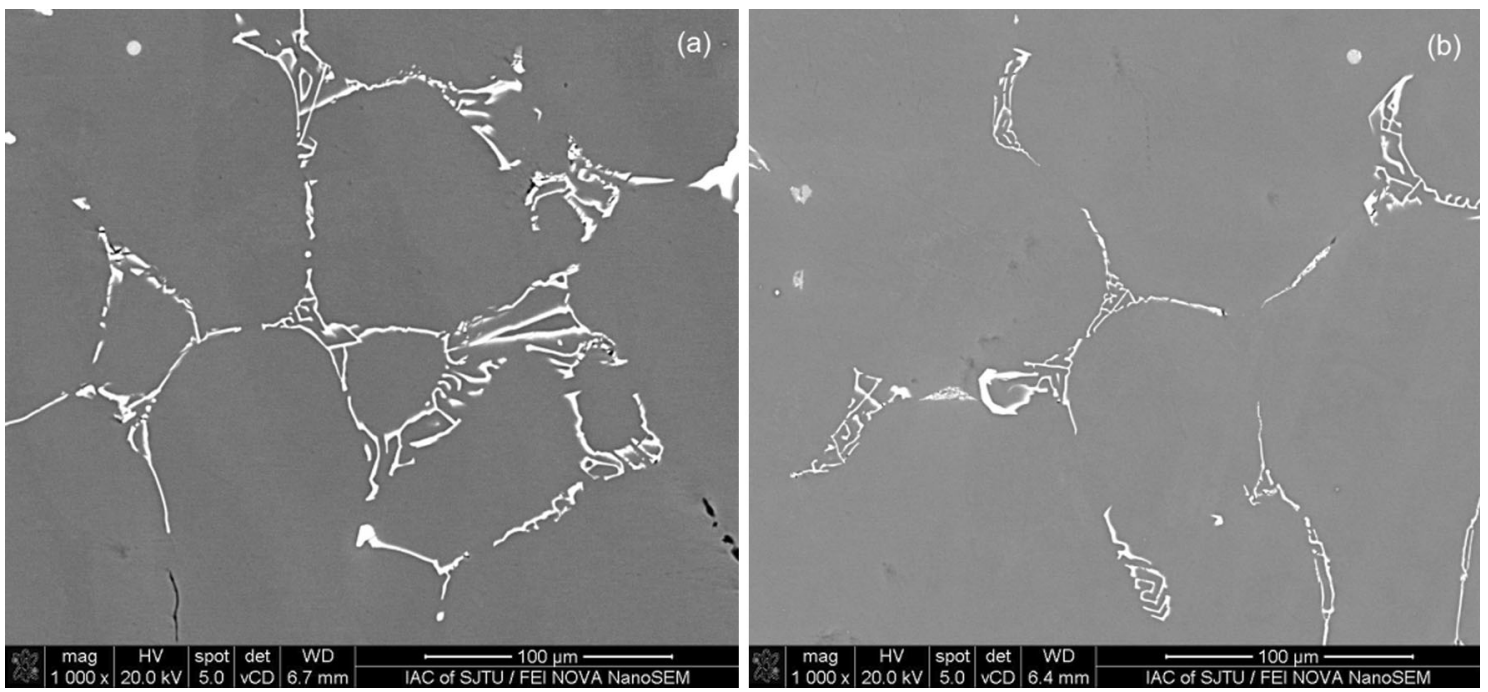

Fig. 5 Micrographs of samples before purification a, after $10 \mathrm{~min}$ of purification at $700{ }^{\circ} \mathrm{C} \mathbf{b}$
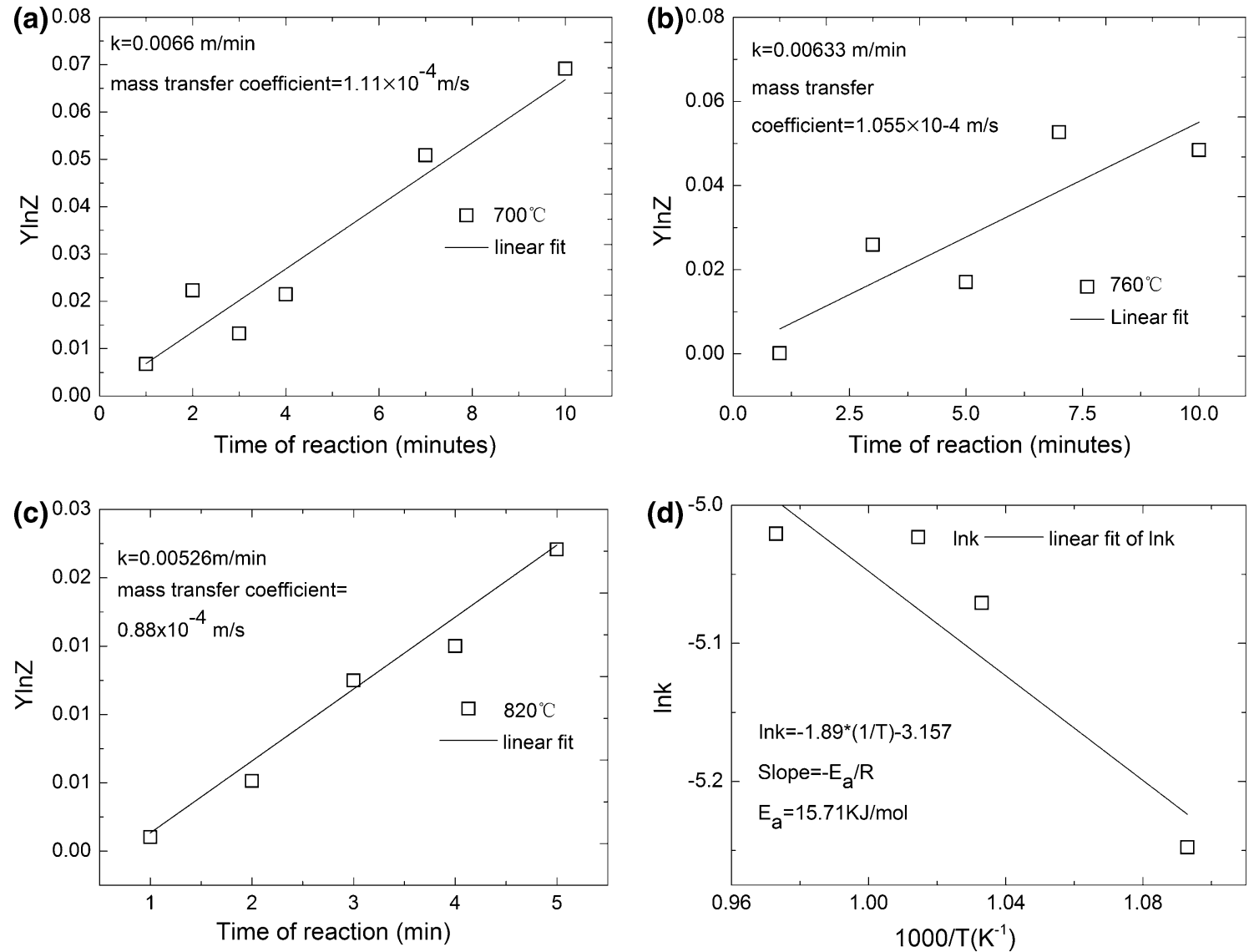

Fig. 6 Integrated rate plot of $25 \mathrm{~g} 0.22 \mathrm{wt} \% \mathrm{Si}$ at a $700{ }^{\circ} \mathrm{C}, \mathbf{b} 760{ }^{\circ} \mathrm{C}, \mathbf{c} 820{ }^{\circ} \mathrm{C}$ in the single-factor experiments, $\mathbf{d}$ a plot between $\ln k$ and $1000 /$ $T$ from the experimental data 


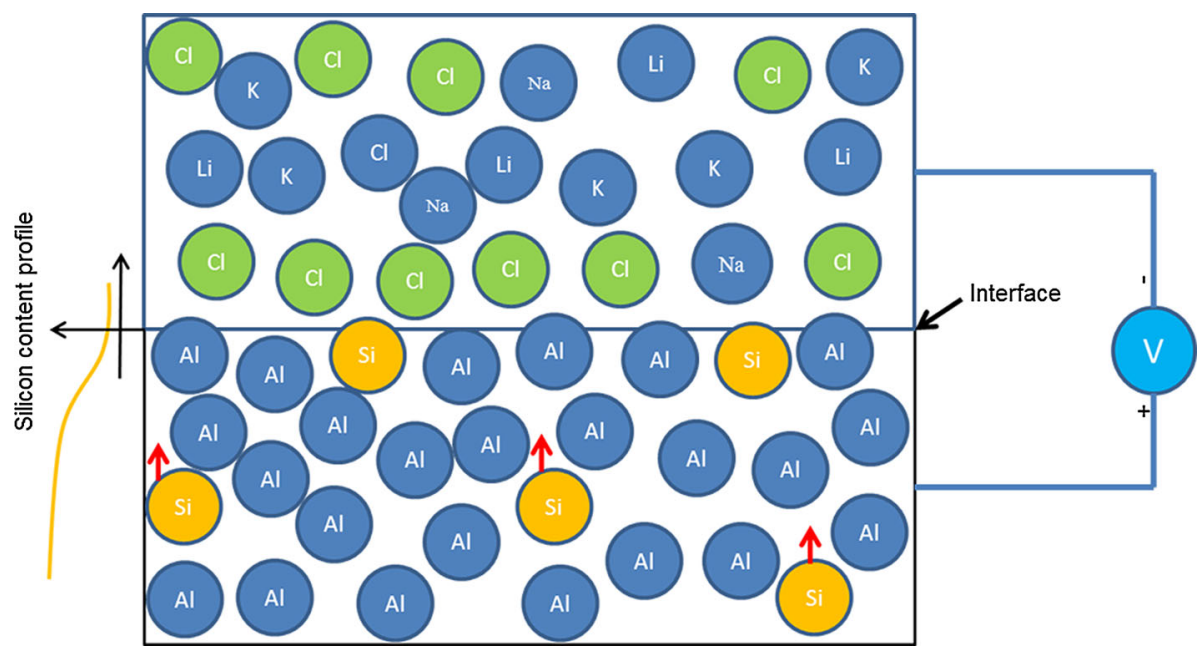

Fig. 7 Diagram of interfacial reaction, $V$ represents the external potential at interface; red arrows represent the direction of mass transfer
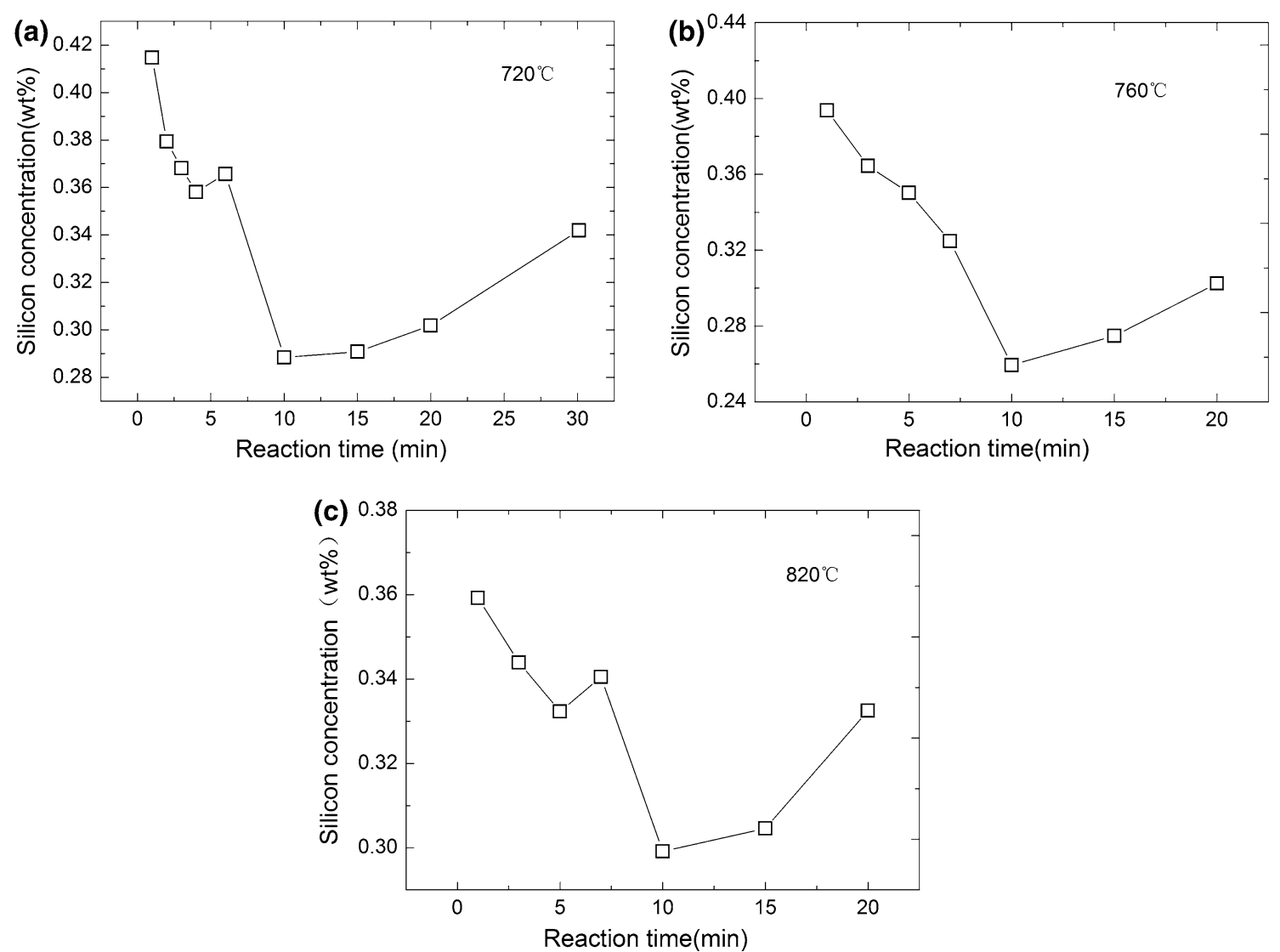

Fig. 8 Temporal variation of silicon concentration in $0.44 \mathrm{wt} \% \mathrm{Si}$ samples at $720{ }^{\circ} \mathrm{C} \mathrm{a}, 760{ }^{\circ} \mathrm{C} \mathbf{b}, 820{ }^{\circ} \mathrm{C}$ c in single-factor experiments

It is inferred that the initial silicon concentration affects the extent of silicon concentration reduction at the interface. The initial silicon concentration should be taken into account if the experimental method is applied to reduce the silicon concentration in aluminum melt.

\subsection{Mass Ratio and Electric Field}

Figure 9a shows that the silicon concentration decreases with the increasing mass ratio. According to our previous research, a gas phase was generated throughout the 

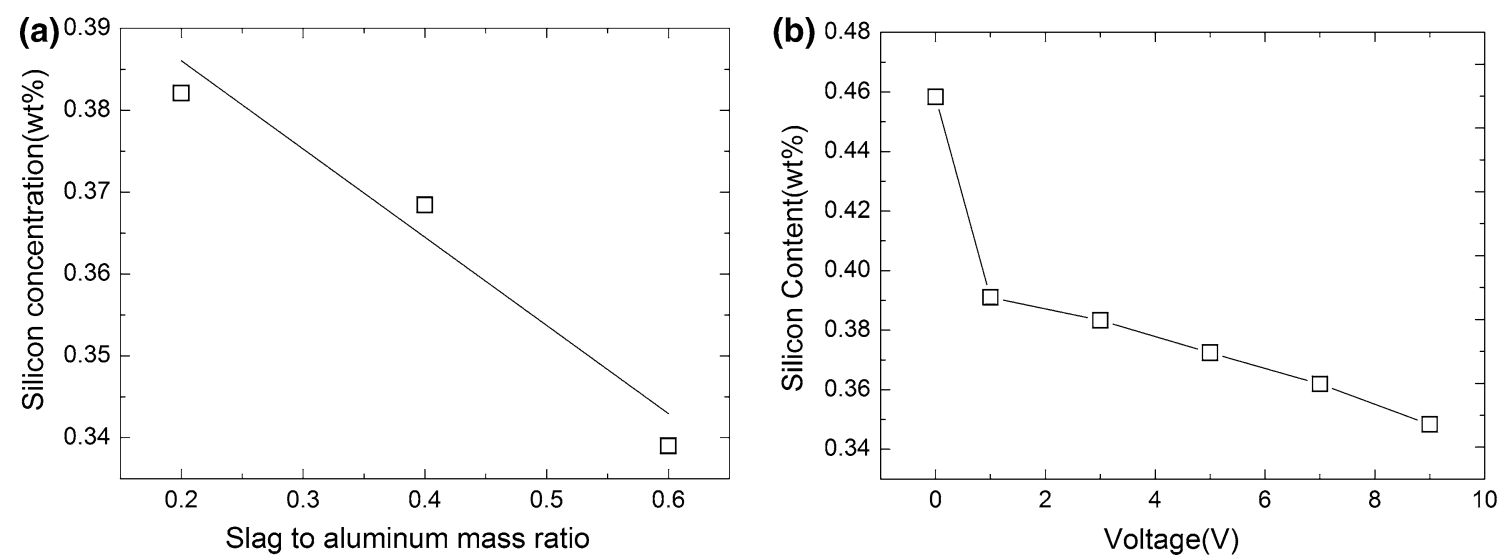

Fig. 9 Changes of silicon concentration with a slag amount, $\mathbf{b}$ voltage in single-factor experiments

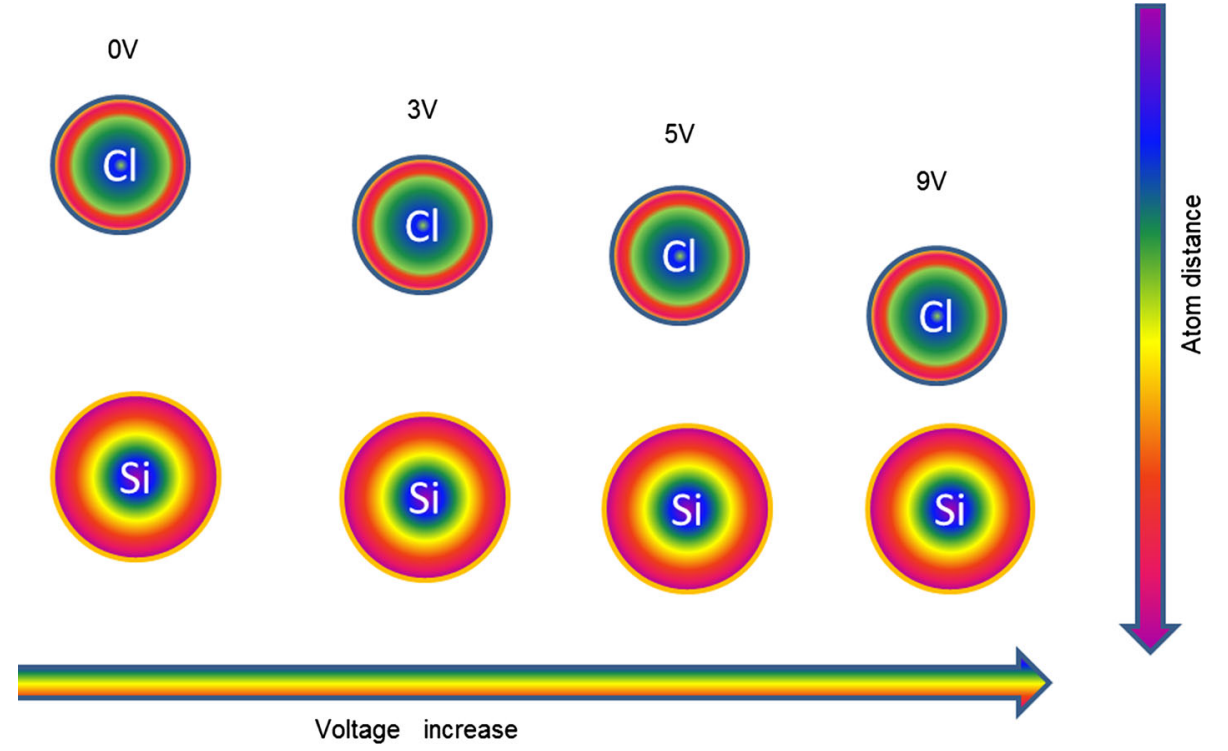

Fig. 10 Reaction probability with increase in voltage

interfacial electrochemical reaction [28] and added perturbation to the current density at the reaction interface. The increase in molten salt concentration suppressed the current fluctuation and promoted the formation of a stable and continuous interfacial reaction.

The rapid reduction in silicon concentration from voltage 0 to $1 \mathrm{~V}$ in Fig. $9 \mathrm{~b}$ indicates the crucial role of the electric field in the interfacial reaction. The silicon concentration decreases continuously from voltage 1 to $9 \mathrm{~V}$, which is generally a result of the accelerated reaction. As reported, the contribution of the electric field to the electrode interfacial reaction can be explained by two equations [29, 30]:

$W_{2}=W_{2}^{0}-\beta n F \Delta \varphi$,

$\bar{i}=n k_{2}^{0} C_{O} e^{\beta n F \Delta \varphi / R T}$.

Specifically, Eq. (4) reveals the change of activation energy at the anodic electrode, where $W_{2}^{0}$ is the activation energy without polarization, $n$ is the change of electron number, and $F$ is the Faraday constant. With the elevation of voltage, the interfacial current density and thereby the polarized potential $\Delta \varphi$ increase, decreasing the activation energy and improving the reaction conditions. The reaction rate of the electrode kinetic process is usually represented by the electric current density [31], as shown in Eq. (5). It can be inferred from Eq. (5) that the increase in electrode potential would intensify the current density. In other words, a high voltage accelerates the aluminum-slag interfacial reaction.

The above discussion indicates that the increment of interfacial voltage would increase the polarized potential, which in turn accelerates the electron transfer. Thus, the elevation of polarized potential increases the probability of interfacial reaction. Also, the probability of collisions between silicon and chlorine atoms is increased according 
to the effective collision theory $[32,33]$. Equivalently, the atomic distance is shortened with the increase in polarized potential (Fig. 10). To some extent, Fig. 10 explains why the voltage contributes to the interfacial reaction.

\section{Conclusions}

The influences of external factors on aluminum-slag interfacial reaction under electric field were studied through orthogonal experiments. The significance of the tested influence factors ranks as $t>\mathrm{NB}>\mathrm{LiCl}=$ $V>T>R$. Single-factor experiments suggest that the reaction kinetics obeys an irreversible kinetic model and the rate-controlling step is silicon mass transfer. Voltage significantly affects the interfacial reaction and silicon removal efficiency, and the mass ratio only marginally improves the silicon removal efficiency.

Acknowledgements This research is supported by National Natural Science Foundation of China (Grant Nos. 51274141,51204110); National Basic Research Program of China (Grant No. 2012CB619505); and Science and Technology Commission of Shanghai Municipality (STCSM) for high-tech project (Grant Nos. 15111108000).

\section{References}

[1] R. Kumar, A. Bhattacharya, T.K. Bera, Mater. Manuf. Process. 30, 1146 (2015)

[2] D. Narsimhachary, R.N. Bathe, G. Padmanabham, A. Basu, Mater. Manuf. Process. 29, 948 (2014)

[3] C. Lee, T. So, K. Shin, Acta Metall. Sin. (Engl. Lett.) 29, 638 (2016)

[4] T. Cai, Z.J. Zhang, J.B. Yang, Z.F. Zhang, Acta Metall. Sin. (Engl. Lett.) 29, 647 (2016)

[5] Z.Y. Ye, D.X. Liu, M. Yuan, X.M. Zhang, Z. Yang, M.X. Lei, Acta Metall. Sin. (Engl. Lett.) 28, 608 (2015)

[6] X.G. An, Y. Liu, J.W. Ye, L.Z. Wang, P.Y. Wang, Acta Metall. Sin. (Engl. Lett.) 29, 742 (2016)

[7] B.W. Zhang, Z.M. Ren, J.X. Wu, T. Nonferr, Metal. Soc. 16, 33 (2006)
[8] L.N.W. Damoah, Dissertation, Missouri University of Science and Technology (2012)

[9] T.R. Prabhu, Acta Metall. Sin. (Engl. Lett.) 28, 909 (2015)

[10] B. Patchett, D. Milner, Weld. J. 51, 491 (1972)

[11] A. Mitchell, G. Beynon, Metall. Mater. Trans. B 2, 3333 (1971)

[12] A. Troyanskyy, Investigation of Mass Transfer Processes Between Metal and Slag at Film Stage of ESR Process. Paper presented at proceeding of international symposiums \& workshops on metallurgy (Ukraine, 2011)

[13] A. Mitchell, M. Bell, Can. Metall. Quart. 11, 363 (1972)

[14] C. Chen, J. Wang, D. Shu, S. Zhang, B. Sun, Mater. Trans. 52, 2266 (2011)

[15] R. Pomfret, P. Grieveson, Can. Metall. Quart. 22, 287 (1983)

[16] L. Muhmood, N.N. Viswanathan, S. Seetharaman, Metall. Mater. Trans. B 42, 393 (2011)

[17] H.S. Jang, J.W. Ryu, I. Sohn, Metall. Mater. Trans. B 46, 606 (2015)

[18] K.K. Deng, J.C. Li, J.F. Fan, X.J. Wang, K. Wu, B.S. Xu, Acta Metall. Sin. (Engl. Lett.) 27, 885 (2014)

[19] J. Park, S. Sridhar, R.J. Fruehan, Metall. Mater. Trans. B 45, 1380 (2014)

[20] J. White, D. Sichen, Metall. Mater. Trans. B 45, 96 (2014)

[21] N.W. Dai, J.X. Zhang, Q.M. Chen, X. Zhang, F.H. Cao, J.Q. Zhang, Acta Metall. Sin. (Engl. Lett.) 29, 373 (2016)

[22] M.S. Bafghi, A. Asghari, A. Zakeri, S. Seyedein, Metall. Mater. Trans. B 40, 749 (2009)

[23] J.Z. Zhao, T. Ahmed, H.X. Jiang, J. He, Q. Sun, Acta Metall. Sin. (Engl. Lett.) 30, 1 (2017)

[24] D. Sri Maha Vishnu, N. Sanil, K.S. Mohandas, K. Nagarajan, Acta Metall. Sin. (Engl. Lett.) 30, 218 (2016)

[25] B. Jiang, W. Wang, I. Sohn, J. Wei, L. Zhou, B. Lu, Metall. Mater. Trans. B 45, 1057 (2014)

[26] Y. Du, Y.A. Chang, B. Huang, W. Gong, Z. Jin, H. Xu, Z. Yuan, Y. Liu, Y. He, F.Y. Xie, Mater. Sci. Eng. A Struct. 363, 140 (2003)

[27] Y. Sun, M. Zhang, W. Han, M. Li, Y. Yang, Y. Yan, M. Zhang, Acta Metall. Sin. (Engl. Lett.) 26, 455 (2013)

[28] Y. Lu, J. Dong, W. Ke, J. Mater. Sci. Technol. 32, 341 (2016)

[29] D.S. Samuel Glasstone, Ph.D., An Introduction To Electrochemistry (Tenth Printing) (Litton Educational New York, New York, 2008), pp. 460-462

[30] J. Wang, Analytical Electrochemistry (Wiley-VCH, Hoboken, 2006), pp. 13-14

[31] R. Kotoka, S. Yarmolenko, D. Pai, J. Sankar, J. Mater. Sci. Technol. 31, 873 (2015)

[32] F.R.W. McCourt, V. Vesovic, W.A. Wakeham, A.S. Dickinson, M. Mustafa, Mol. Phys. 72, 1347 (1991)

[33] Q.S. Ma, Y.C. Jin, Y.H. Zhao, H.M. Sui, P. Zhang, Acta Metall. Sin. (Engl. Lett.) 29, 975 (2016) 